\title{
Negative impact of anorexia and weight loss during prior pirfenidone administration on subsequent nintedanib treatment in patients with idiopathic pulmonary fibrosis
}

Satoshi Ikeda ${ }^{1 *}$ D, Akimasa Sekine ${ }^{1}$, Tomohisa Baba ${ }^{1}$, Takuma Katano $^{1}$, Erina Tabata ${ }^{1}$, Ryota Shintani ${ }^{1}$, Shinko Sadoyama', Hideaki Yamakawa', Tsuneyuki Oda', Ryo Okuda'? Hideya Kitamura', Tae Iwasawa², Tamiko Takemura ${ }^{3}$ and Takashi Ogura'

\begin{abstract}
Background: Current clinical practice guidelines for idiopathic pulmonary fibrosis (IPF) conditionally recommend use of pirfenidone and nintedanib. However, an optimal treatment sequence has not been established, and the data of treatment sequence from pirfenidone to nintedanib are limited. This study aimed to evaluate safety, tolerability and efficacy of nintedanib switched from pirfenidone in patients with IPF.
\end{abstract}

Methods: Thirty consecutive IPF cases, which discontinued pirfenidone because of a decline in forced vital capacity (FVC) or intolerable adverse event (AE), and newly started nintedanib (150 mg twice daily) from September 2015 to August 2017 (switch-group) were retrospectively reviewed. Subsequently, we compared the characteristics, treatment status, and AEs between the switch-group and other 64 IPF patients newly started nintedanib during the same period without any prior anti-fibrotic treatment (pirfenidone-naïve group).

Results: In the switch group, median age, body weight, body mass index (BMI), and \%FVC were 72 years old, $54.9 \mathrm{~kg}$, $21.0 \mathrm{~kg} / \mathrm{m}^{2}$, and $52.9 \%$, respectively. Most common AE of nintedanib was aspartate aminotransferase/alanine aminotransferase elevation (71.9\%), followed by anorexia (46.7\%) and diarrhea (46.7\%); whereas, anorexia (63.3\%) and $\geq 5 \%$ weight loss from baseline (56.7\%) were common during pirfenidone administration. Sixteen patients (53.3\%) discontinued nintedanib within 6 months (early termination). Multivariate logistic regression analysis revealed a significant association between low BMl and early nintedanib termination in the switch-group $(p=0.0239)$. Nintedanib suppressed FVC decline as compared with that during administration period of pirfenidone in $70 \%$ of the patients who could undergo lung function before and after switching to nintedanib. The incidence of early termination of nintedanib was higher in the switch-group than in the pirfenidone-naïve group, whereas body-weight, BMI, absolute FVC values, and \%FVC were significantly lower in the switch-group (just before nintedanib initiation) than in the pirfenidone-naïve group. Nintedanib-induced anorexia was more frequent and severer in the switch-group than in the pirfenidone-naïve group, but no significant differences were observed in terms of other AEs.

Conclusions: A high incidence of early termination of nintedanib was noted when patients were switched from pirfenidone. Anorexia and weight loss during prior pirfenidone administration may increase the rate of the early termination of subsequent nintedanib treatment.

Keywords: Nintedanib, Pirfenidone, Early termination, Adverse event, Anorexia, Weight loss

\footnotetext{
* Correspondence: isatsohi0112@gmail.com

'Department of Respiratory Medicine, Kanagawa Cardiovascular and

Respiratory Center, Tomioka-Higashi 6-16-1, Kanazawa-ku, Yokohama

236-0051, Japan

Full list of author information is available at the end of the article
}

(c) The Author(s). 2019 Open Access This article is distributed under the terms of the Creative Commons Attribution 4.0 International License (http://creativecommons.org/licenses/by/4.0/), which permits unrestricted use, distribution, and reproduction in any medium, provided you give appropriate credit to the original author(s) and the source, provide a link to the Creative Commons license, and indicate if changes were made. The Creative Commons Public Domain Dedication waiver (http://creativecommons.org/publicdomain/zero/1.0/) applies to the data made available in this article, unless otherwise stated. 


\section{Background}

The development of two anti-fibrotic drugs, pirfenidone and nintedanib, has markedly changed the management of idiopathic pulmonary fibrosis (IPF) over the last decade $[1,2]$. These drugs have been shown to reduce the decline in forced vital capacity (FVC) among IPF patients with a manageable side-effect profile [3-5] and have received a conditional recommendation for use according to the current clinical practice guidelines of IPF [6]. In addition, nintedanib is expected to restrain the acute exacerbation of IPF; in the INPULSIS ${ }^{\bullet}$ trials, prespecified verification by a central adjudication committee indicated that the risk of acute exacerbation of IPF was significantly lower in the nintedanib group than in the placebo group [4, 7]. A meta-analysis of IPF therapy also revealed that nintedanib, not pirfenidone or NAC, significantly reduced the risk of acute exacerbations development [8]. Moreover, an interim analysis of the INPULSIS ${ }^{\circ}$-ON trial indicated that the beneficial effect of nintedanib on slowing disease progression was maintained and the change from baseline FVC was consistent over a long period [9]. On the other hand, pirfenidone has been shown to reduce both all-cause and IPF related mortality in a pre-specified pooled analysis of CAPACITY and ASCEND trials (hazard ratios 0.52 and 0.32 , respectively) [10]. Because treatment options for IPF are limited, these two anti-fibrotic drugs should be maximally utilized. However, an optimal treatment sequence has not yet been established. Only one retrospective case series study involving the switching of pirfenidone to nintedanib has been performed [11]. This study indicated that IPF patients switched from pirfenidone due to adverse events (AEs) showed good tolerance of nintedanib, and the intra-individual responses to the two drugs may differ. However, this study had a preliminary nature because of its small sample size $(N=7)$.

The present study evaluated the safety, tolerability, and efficacy of nintedanib in IPF patients switched from pirfenidone to nintedanib for establishing an optimal treatment strategy for IPF in the future.

\section{Methods}

\section{Patients and settings}

This retrospective study was performed at Kanagawa Cardiovascular and Respiratory Center in Yokohama, Japan. All consecutively enrolled patients had (1) IPF diagnosed based on the official American Thoracic Society/European Respiratory Society/Japanese Respiratory Society/Latin American Thoracic Association statement of 2011 [12], (2) discontinued pirfenidone due to a decline in FVC or intolerable AEs despite dose modification or symptomatic therapy, and (3) newly started nintedanib (150 mg twice daily) during September 2015-August 2017. Patients with a history of receiving anti-fibrotic treatments other than pirfenidone or advanced lung cancer complications were excluded. Subsequently, we compared the characteristics, treatment status, and AEs between the aforementioned study participants (switch-group) and other IPF patients who had newly started nintedanib at a dose of $150 \mathrm{mg}$ twice daily during September 2015-August 2017 at our hospital and were without any prior anti-fibrotic treatment or advanced lung cancer complications (pirfenidone-naïve group). This study was performed in accordance with the Declaration of Helsinki. The Ethics Committee of the Kanagawa Cardiovascular and Respiratory Center approved the study protocol (approval date: January 16, 2018; approved number: KCRC-17-0040), and the need for patient consent was waived because this was a retrospective study and anonymity was secured.

\section{Data availability}

The datasets generated and/or analyzed during this study are available from the corresponding authors on reasonable request.

\section{Clinical and laboratory findings}

The clinical and laboratory data were retrieved from patient medical records. Age, gender, height, body weight, laboratory data [aspartate aminotransferase (AST), alanine aminotransferase (ALT), alkaline phosphatase, total bilirubin, $\gamma$-glutamyl transpeptidase, serum creatinine, Krebs von den Lungen-6 (KL-6), and Surfactant protein-D (SP-D)], pulmonary function tests, and concomitant therapy were evaluated. Serum levels of KL-6 and SP-D were measured using chemiluminescent enzyme immunoassay system (BML, Inc. Shibuya-ku, Tokyo, Japan).

\section{Assessment of and response to AEs}

The grading of worst examination values of AEs was based on the Common Terminology Criteria for Adverse Events (CTCAE) ver. 4.0 [13]. When a patient developed AEs, treatment interruption or dose reduction was performed in accordance with the guideline for the appropriate use of nintedanib $\left(\mathrm{Ofev}^{\bullet}\right)$ [14].

\section{Statistical analysis}

Categorical data are presented as numbers (percentages), and compared using Fisher's exact test. Continuous data are presented as medians (interquartile ranges), and compared using Mann-Whitney U test. A multivariate logistic regression analysis was performed to verify the risk. A $p$ value of $<0.05$ was considered statistically significant. All statistical analyses were performed using EZR (Saitama Medical Center, Jichi Medical University, Saitama, Japan) [15], which is a graphical user interface for $\mathrm{R}$ version 3.2.2 (The $\mathrm{R}$ Foundation for Statistical Computing, Vienna, Austria). 


\section{Results}

\section{Characteristics}

Thirty IPF patients were enrolled in this study and patient characteristics observed just before initiating nintedanib are summarized in Table 1. Most of the included patients were males $(76.5 \%)$ and the median age was 72 years old. The median body weight, body mass index (BMI), and body surface area (BSA) estimated using the $\mathrm{Du}$ Bois formula were $54.9 \mathrm{~kg}, 21.0$, and $1.59 \mathrm{~m}^{2}$, respectively. The median percent predicted FVC (\%FVC)

Table 1 Patient characteristics

\begin{tabular}{|c|c|c|c|}
\hline & \multirow{2}{*}{$\begin{array}{l}\text { Present study } \\
(n=30)\end{array}$} & \multicolumn{2}{|c|}{ Nintedanib group in INPULSIS trials } \\
\hline & & Japanese $(n=76)$ & Overall $(n=638)$ \\
\hline \multicolumn{4}{|l|}{ Baseline characteristics } \\
\hline Age & $72.0[68.0,74.8]$ & $68.4 \pm 7.6^{\mathrm{a}}$ & $66.6 \pm 8.1^{\mathrm{a}}$ \\
\hline Gender (male/female) & $24 / 6$ & $62 / 14$ & $507 / 131$ \\
\hline Current or former smoker (\%) & $26(86.7 \%)$ & $66(86.8 \%)$ & $464(72.7 \%)$ \\
\hline \multicolumn{4}{|l|}{ Physique } \\
\hline Body weight (kg) & $54.9[49.7,64.4]$ & $63.8 \pm 11.6^{a}$ & $79.2 \pm 16.6^{\mathrm{a}}$ \\
\hline Body mass index & $21.0[19.0,23.6]$ & $24.4 \pm 3.4^{\mathrm{a}}$ & $28.1 \pm 4.6^{\mathrm{a}}$ \\
\hline Body surface area (DuBois, m²) & $1.59[1.48,1.72]$ & - & - \\
\hline \multicolumn{4}{|l|}{ Concomitant therapy } \\
\hline Prednisolone (\%) & $3(10.0 \%)$ & $9(11.8 \%)$ & $136(21.3 \%)$ \\
\hline Tacrolimus (\%) & $1(3.3 \%)$ & 0 & 0 \\
\hline \multicolumn{4}{|l|}{ Laboratory data } \\
\hline Aspartate aminotransferase (IU/L) & $21.5[18.0,24.8]$ & - & - \\
\hline Alanine aminotransferase (IU/L) & $16.0[11.0,24.3]$ & - & - \\
\hline Total bilirubin (mg/dL) & $0.50[0.30,0.60]$ & - & - \\
\hline Y-glutamyl transpeptidase (IU/L) & $31.0[21.3,48.0]$ & - & - \\
\hline Creatinine (mg/dL) & $0.80[0.68,0.87]$ & - & - \\
\hline Krebs von den Lungen-6 (U/mL) & $1021[829,1903]$ & - & - \\
\hline Surfactant protein D (ng/dL) & $382[259,452]$ & - & - \\
\hline \multicolumn{4}{|l|}{ Lung function test } \\
\hline Forced vital capacity (L) & $1.68[1.34,1.99]$ & $2.42 \pm 0.67^{\mathrm{a}}$ & $2.71 \pm 0.76^{\mathrm{a}}$ \\
\hline$\%$ Forced vital capacity (\%) & $52.9[43.7,69.7]$ & $80.9 \pm 16.6^{\mathrm{a}}$ & $79.7 \pm 17.6^{\mathrm{a}}$ \\
\hline$\%$ DLco (\%) & $44.2[40.9,58.5]$ & $44.6 \pm 11.4^{\mathrm{a}}$ & $47.4 \pm 13.5^{\mathrm{a}}$ \\
\hline \multicolumn{4}{|l|}{ Administration history of pirfenidone } \\
\hline Administration period (months) & $8.30[4.23,13.9]$ & - & - \\
\hline \multicolumn{4}{|c|}{ Time from discontinuation to nintedanib initiation } \\
\hline 0 (direct switch) & $20(66.6 \%)$ & - & - \\
\hline$<1$ month & $3(10.0 \%)$ & - & - \\
\hline$\geq 1$ month & $7(23.3 \%)$ & - & - \\
\hline \multicolumn{4}{|l|}{ Reason for discontinuation (\%) } \\
\hline Decline of FVC & $15(50.0 \%)$ & - & - \\
\hline Adverse events & $15(50.0 \%)$ & - & - \\
\hline \multicolumn{4}{|l|}{ Maintenance dose (\%) } \\
\hline$<1200 \mathrm{mg}$ & $10(33.3 \%)$ & - & - \\
\hline 1200 mg & $16(53.3 \%)$ & - & - \\
\hline 1800 mg & $4(13.3 \%)$ & - & - \\
\hline
\end{tabular}

Categorical data are presented as numbers (percentages) and continuous data are presented as medians (interquartile ranges) Abbreviation: DLco diffusing capacity for lung carbon monoxide

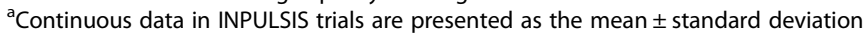


and percent predicted diffusing capacity for lung carbon monoxide (\%DLco) at baseline were 52.9 and 44.2\%, respectively. The physique-related factors, absolute FVC values, and \%FVC were considerably lower than those reported in the INPULSIS trials; as for the Japanese patients of nintedanib group in the INPULSIS trials, the mean body weight, $\mathrm{BMI}$, absolute $\mathrm{FVC}$ value, and \%FVC were $63.8 \mathrm{~kg}, 24.4,2.42 \mathrm{~L}$, and $80.9 \%$, respectively. Twenty-seven patients (90\%) revealed definite usual interstitial pneumonia pattern on high-resolution computed tomography, and 8 patients $(26.7 \%)$ have undergone surgical lung biopsy for the diagnosis of IPF.

Twenty-three patients $(76.6 \%)$ were switched to nintedanib with an interruption period of less than 1 month, and the median duration of prior pirfenidone treatment was 8.3 months. Fifteen patients (50\%) were switched to nintedanib because of FVC decline and 15 patients (50\%) because of intolerable AEs. The median follow-up duration from the initiation of nintedanib was 10.4 months (data cutoff date was October 4, 2017).

\section{Adverse events}

The details of AEs during the pirfenidone and nintedanib administration periods are summarized in Table 2 . The most common AE of nintedanib was AST / ALT elevation (63.3\%), followed by anorexia (46.7\%), diarrhea (46.7\%), and weight loss (20.0\%), whereas the most common CTCAE grade $\geq 2$ AE was anorexia (36.7\%), followed by diarrhea (26.7\%) and AST/ALT elevation (23.3\%). By contrast, during the pirfenidone administration period, 19 patients (63.3\%) exhibited anorexia, and 16 patients $(53.3 \%)$ had a CTCAE grade of $\geq 2$. In addition, 17 patients (56.7\%) exhibited weight loss with a CTCAE grade of $\geq 1$ ( $\geq 5 \%$ from baseline), and seven patients $(23.3 \%)$ had a CTCAE grade of $\geq 2(\geq 10 \%$ from baseline).

\section{Treatment status of nintedanib during the observation period}

The treatment status during the observation period is summarized in Table 3. Eighteen patients (60.0\%) discontinued nintedanib during the observation period. Notably, 16 patients (53.3\%) discontinued nintedanib within 6 months. The most common causes of discontinuation were liver injury, anorexia along with weight loss, deterioration of physical condition, death, and acute exacerbation of IPF $(10 \%$ each). Only 7 patients (23.3\%) continued nintedanib without interruption and/or dose reduction.

\section{Efficacy of nintedanib in patients switched from pirfenidone}

Figure 1 shows the decline of FVC per month during the periods of pirfenidone administration [(FVC value just before nintedanib initiation - most recent FVC value during

Table 2 Adverse events during the pirfenidone and nintedanib administration periods

\begin{tabular}{|c|c|c|c|c|c|c|c|c|}
\hline & \multicolumn{4}{|c|}{ During the pirfenidone administration period $(n=30)$} & \multicolumn{4}{|c|}{ During the nintedanib administration period $(n=30)$} \\
\hline & \multirow[t]{2}{*}{ Subjects } & \multicolumn{3}{|c|}{ CTCAE grade } & \multirow[t]{2}{*}{ Subjects } & \multicolumn{3}{|c|}{ CTCAE grade } \\
\hline & & 1 & 2 & 3 & & 1 & 2 & 3 \\
\hline \multicolumn{9}{|l|}{ Gastrointestinal } \\
\hline Anorexia & $19(63.3 \%)$ & 3 & 14 & 2 & $14(46.7 \%)$ & 3 & 8 & 3 \\
\hline Weight loss & $17(56.7 \%)$ & 10 & 5 & 2 & $6(20.0 \%)$ & 3 & 3 & 0 \\
\hline Diarrhea & 0 & 0 & 0 & 0 & $14(46.7 \%)$ & 6 & 7 & 1 \\
\hline Dyspepsia & $5(16.7 \%)$ & 1 & 4 & 0 & 0 & 0 & 0 & 0 \\
\hline Nausea & 0 & 0 & 0 & 0 & $2(6.7 \%)$ & 0 & 2 & 0 \\
\hline Vomiting & 0 & 0 & 0 & 0 & $2(6.7 \%)$ & 2 & 0 & 0 \\
\hline \multicolumn{9}{|l|}{ Other } \\
\hline AST/ALT elevation & $1(3.3 \%)$ & 0 & 0 & 1 & 19 (63.3\%) & 12 & 5 & 2 \\
\hline Fatigue & $5(16.7 \%)$ & 1 & 4 & 0 & $3(10.0 \%)$ & 1 & 1 & 1 \\
\hline Photosensitivity & $3(10.0 \%)$ & 2 & 0 & 1 & 0 & 0 & 0 & 0 \\
\hline Rash & $2(6.7 \%)$ & 2 & 0 & 0 & 0 & 0 & 0 & 0 \\
\hline Abdominal pain & 0 & 0 & 0 & 0 & $3(10.0 \%)$ & 2 & 1 & 0 \\
\hline Back pain & $2(6.7 \%)$ & 0 & 2 & 0 & 0 & 0 & 0 & 0 \\
\hline Non-cardiac chest pain & $1(3.3 \%)$ & 1 & 0 & 0 & 0 & 0 & 0 & 0 \\
\hline Fever & 0 & 0 & 0 & 0 & $2(6.7 \%)$ & 2 & 0 & 0 \\
\hline Acute exacerbation & 0 & 0 & 0 & 0 & $2(6.7 \%)$ & 0 & 0 & 2 \\
\hline
\end{tabular}

Categorical data are presented as numbers (percentages)

Abbreviations: AST aspartate aminotransferase, ALT alanine aminotransferase, CTCAE Common Terminology Criteria for Adverse Events 
Table 3 Treatment status of nintedanib switched from pirfenidone

\begin{tabular}{ll}
\hline & $(n=30)$ \\
\hline Administration period of nintedanib (months) & $5.30[2.84,11.8]$ \\
Discontinued & $18(60.0 \%)$ \\
Discontinued within 6 months & $16(53.3 \%)$ \\
Reason for discontinuation & \\
Liver injury & $3(10.0 \%)$ \\
Anorexia + weight loss & $3(10.0 \%)$ \\
Deterioration of physical condition & $3(10.0 \%)$ \\
Death & $3(10.0 \%)$ \\
Acute exacerbation of IPF & $3(10.0 \%)$ \\
Diarrhea & $1(3.3 \%)$ \\
Nausea & $1(3.3 \%)$ \\
Rash & $1(3.3 \%)$ \\
Continued & $12(40.0 \%)$ \\
Continued without interruption/dose reduction & $7(23.3 \%)$ \\
Need at least $\geq 1$ interruption and/or dose reduction & $5(16.7 \%)$ \\
Reason for interruption and/or dose reduction & \\
Liver injury & $2(6.7 \%)$ \\
Diarrhea & $2(6.7 \%)$ \\
Fever & $1(3.3 \%)$ \\
\hline
\end{tabular}

Categorical data are presented as numbers (percentages)

Abbreviation: IPF idiopathic pulmonary fibrosis pirfenidone administration period) / examination interval] and the decline of FVC per month after switching to nintedanib [(FVC value at 6 months after nintedanib initiation FVC value just before nintedanib initiation) / examination interval]. Only 10 patients could undergo lung function tests at 6 months after switching to nintedanib. However, in 7 of 10 patients (70\%), nintedanib suppressed FVC decline compared with that observed during the pirfenidone administration period.

\section{Risk factors for the early termination of nintedanib}

As stated, 16 patients (53.3\%) discontinued nintedanib within 6 months (early termination group), whereas 14 patients (46.7\%) received nintedanib for $\geq 6$ months (continuous treatment group). A comparison of the clinical and laboratory data between the two groups (Table 4) revealed that BMI and body weight were significantly lower in the early termination group than in the continuous treatment group $(p=0.007$ and 0.048 , respectively). Logistic regression analysis was performed to verify the risk factors for the early termination of nintedanib (Table 5). Univariate analysis identified a significant association between low BMI and early termination of nintedanib $(p=0.0239)$. We selected BMI not only as the most likely candidate risk factor but also as a representative factor related to physique. We also selected weight loss with a CTCAE grade of $\geq 2$ occurring during the pirfenidone administration period and surfactant protein D (SP-D) (both $P \leq 0.1$ in univariate analysis) as candidate risk factors. Multivariate logistic regression analysis using backward stepwise selection revealed a

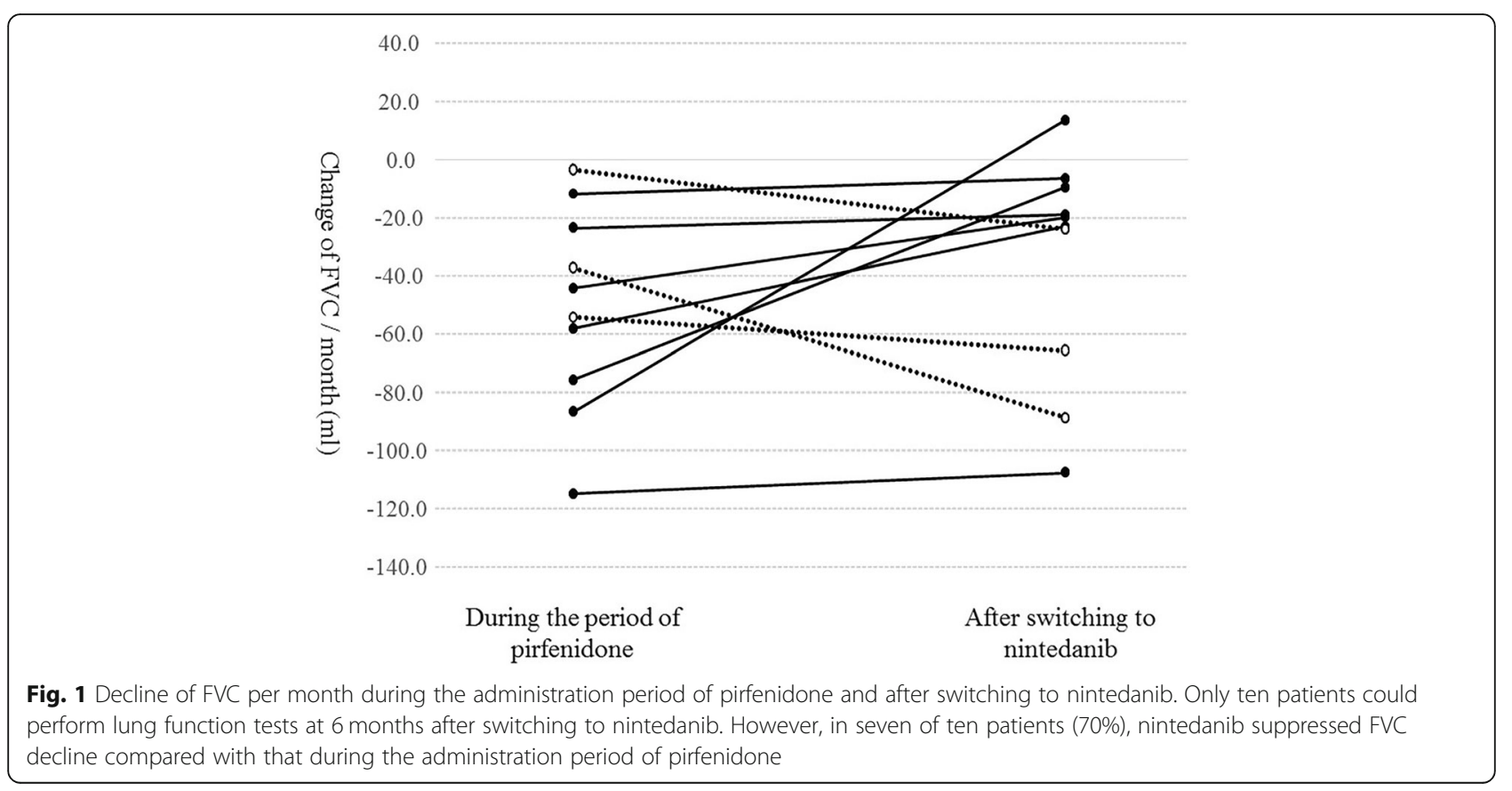


Table 4 Comparison between the early termination and continuous treatment groups

\begin{tabular}{|c|c|c|c|}
\hline & Early termination group $(n=16)$ & Continuous treatment group $(n=14)$ & $p$ value \\
\hline \multicolumn{4}{|l|}{ Baseline characteristics } \\
\hline Age & $73.0[67.5,76.5]$ & $71.5[68.0,74.0]$ & 0.601 \\
\hline Gender (male/female) & $13 / 3$ & $11 / 3$ & 1.00 \\
\hline \multicolumn{4}{|l|}{ Physique } \\
\hline Body weight (kg) & $52.6[47.7,57.8]$ & $58.5[54.5,66.3]$ & 0.048 \\
\hline Body mass index & $19.1[17.2,21.1]$ & $21.9[21.0,24.2]$ & 0.007 \\
\hline Body surface area (DuBois, m²) & $1.58[1.47,1.66]$ & $1.65[1.51,1.77]$ & 0.19 \\
\hline \multicolumn{4}{|l|}{ Laboratory data } \\
\hline Creatinine $(\mathrm{mg} / \mathrm{dL})$ & $0.81[0.68,0.87]$ & $0.74[0.68,0.86]$ & 0.852 \\
\hline Krebs von den Lungen- $6(\mathrm{U} / \mathrm{mL})$ & $1021[732,1518]$ & $1047[845,2106]$ & 0.678 \\
\hline Surfactant protein D (ng/dL) & $315[186,393]$ & $420[273,553]$ & 0.081 \\
\hline \multicolumn{4}{|l|}{ Lung function test } \\
\hline \% Forced vital capacity (\%) & $48.5[36.5,58.6]$ & $56.6[50.1,69.7]$ & 0.212 \\
\hline \% DLco (\%) & $45.1[41.9,58.6]$ & $42.4[37.8,53.3]$ & 0.499 \\
\hline \multicolumn{4}{|l|}{ Administration history of pirfenidone } \\
\hline Administration period (day) & $238[146,468]$ & $262[127,397]$ & 0.934 \\
\hline \multicolumn{4}{|l|}{ Reason for discontinuation (\%) } \\
\hline decline of forced vital capacity & $6(37.5 \%)$ & $9(64.3 \%)$ & 0.272 \\
\hline adverse events & $10(62.5 \%)$ & $5(35.7 \%)$ & \\
\hline \multicolumn{4}{|l|}{ Maintenance dose (\%) } \\
\hline$<1200 \mathrm{mg}$ & $8(50.0 \%)$ & $2(14.3 \%)$ & 0.099 \\
\hline 1200 mg & $5(31.2 \%)$ & $11(78.6 \%)$ & \\
\hline 1800 mg & $3(18.8 \%)$ & 1 (7.1\%) & \\
\hline
\end{tabular}

Categorical data are presented as numbers (percentages), whereas continuous data are presented as medians (interquartile ranges). Fisher's exact test was used to compare categorical data, and the Mann-Whitney $\mathrm{U}$ test was used to compare continuous data

Abbreviation: DLCO diffusing capacity for lung carbon monoxide

statistically significant association between BMI and the early termination of nintedanib $(p=0.0111)$.

\section{Comparison between the switch and pirfenidone-naïve groups}

A comparison of the baseline characteristics (observed just before nintedanib initiation) and data related to nintedanib therapy between the aforementioned study participants (switch-group, $N=30$ ) and other IPF patients who were newly started on nintedanib without any prior anti-fibrotic treatment at our hospital (pirfenidone-naive group, $N=64$ ) revealed that body weight, BMI, \%FVC, and \%DLco were significantly lower in the switch-group than in the pirfenidone-naïve group (Table 6). Conversely, the incidence of nintedanib-induced anorexia was significantly higher in the switch-group than in the pirfenidonenaive group $(p=0.028)$. Moreover, nintedanib-induced anorexia tended to be more severe in the switch-group than in the pirfenidone-naïve group (Table 7). The proportion of discontinuation of nintedanib within 6 months was also higher in the switch-group than in the pirfenidone-naïve group, although this difference did not reach statistical significance $(p=0.0720)$. However, just before initiating pirfenidone, patients in the switch-group had approximately the same body weight, BMI, BSA, FVC, and DLco values as the baseline values of the pirfenidone-naïve group.

\section{Discussion}

In the present study, as many as $53.3 \%$ of patients discontinued nintedanib within 6 months after switching from pirfenidone. Although risk factors for the early termination of nintedanib in IPF patients have not been fully investigated, the present study demonstrated the following two important clinical observations; first, low BMI was a risk factor for the early termination of nintedanib in the switch group; second, nintedanib-induced anorexia was more frequent and severer in the switchgroup than in the pirfenidone-naïve group, but no significant differences were observed in terms of other AEs.

The present study suggested that a small physique can predict the early termination of nintedanib. In fact, the 
Table 5 Logistic regression analysis for verifying the risk factors for the early termination of nintedanib

\begin{tabular}{|c|c|c|c|c|c|c|}
\hline & \multicolumn{3}{|l|}{ Univariate } & \multicolumn{3}{|l|}{ Multivariate } \\
\hline & Odds ratio & $95 \% \mathrm{Cl}$ & $p$ value & Odds ratio & $95 \% \mathrm{Cl}$ & $p$ value \\
\hline Age & 1.02 & $0.885-1.18$ & 0.751 & & & \\
\hline Gender (male/female) & 1.18 & $0.197-7.08$ & 0.855 & & & \\
\hline Never smoker (\%) & 0.857 & $0.104-7.04$ & 0.886 & & & \\
\hline Body weight (kg) & 0.931 & $0.861-1.01$ & 0.0702 & & & \\
\hline Body mass index & 0.704 & $0.519-0.955$ & 0.0239 & 0.487 & $0.280-0.849$ & 0.0111 \\
\hline Body surface area (DuBois, $\mathrm{m}^{2}$ ) & 0.0418 & $0.000541-3.22$ & 0.152 & & & \\
\hline Creatinine (mg/dL) & 1.07 & $0.0280-40.7$ & 0.972 & & & \\
\hline Krebs von den Lungen- $6(\mathrm{U} / \mathrm{mL})$ & 1 & $0.999-1.00$ & 0.348 & & & \\
\hline Surfactant protein D (ng/dL) & 0.995 & $0.989-1.00$ & 0.08 & 0.997 & $0.990-1.00$ & 0.315 \\
\hline Forced vital capacity (L) & 0.561 & $0.150-2.1$ & 0.391 & & & \\
\hline$\%$ Forced vital capacity (\%) & 0.967 & $0.918-1.02$ & 0.213 & & & \\
\hline$\%$ DLco (\%) & 1.01 & $0.9580-1.06$ & 0.739 & & & \\
\hline Administration period of Pirfenidone & 1 & $0.999-1.00$ & 0.329 & & & \\
\hline Time from pirfenidone discontinuation to nintedanib initiation & 1.01 & $0.994-1.02$ & 0.355 & & & \\
\hline Discontinued pirfenidone due to FVC decline & 0.333 & $0.0751-1.48$ & 0.148 & & & \\
\hline Anorexia during the period of pirfenidone & 1.65 & $0.370-7.37$ & 0.512 & & & \\
\hline Weight loss during the period of pirfenidone & 2.93 & $0.657-13.1$ & 0.159 & & & \\
\hline Weight loss with grade $\geq 2$ during the period of pirfenidone & 7.8 & $0.804-75.6$ & 0.0764 & 3.29 & $0.184-58.8$ & 0.418 \\
\hline
\end{tabular}

Univariate analysis showed that the association between low body mass index and the early termination of nintedanib was statistically significant $(p=0.0239)$. In addition, the association between weight loss with a CTCAE grade of $\geq 2$ during the pirfenidone administration period and the early termination of nintedanib was also marginally significant $(p=0.0764)$. A multivariate logistic regression analysis using backward stepwise selection showed that the association between BMI and the early termination of nintedanib was statistically significant $(p=0.0111)$

Abbreviation: DLCO diffusing capacity for lung carbon monoxide

incidence of early termination of nintedanib in the present study was considerably higher than that in the INPULSIS trials, whereas values of physique-related factors, such as body weight, BMI, and absolute FVC, were considerably lower than those reported in the INPULSIS trials. Similarly, in the present study, the incidence of early termination of nintedanib was higher in the switch-group than in the pirfenidone-naïve group, whereas the values of physique-related factors were significantly lower in the switch-group than in the pirfenidone-naïve group. Interestingly, just before initiating pirfenidone, patients in the switch group had approximately the same body weight, BMI, BSA, and absolute FVC values as the baseline values of the pirfenidone-naïve group. This down-sizing of physique in the present study might have been due to not only the disease progression but also pirfenidone-induced weight loss, and this would be a major problem in the treatment sequence from pirfenidone to nintedanib.

Furthermore, the high incidence of early termination in patients with a small physique may have been because of the increase in the incidence and severity of AEs. We previously reported that a high incidence of hepatotoxicity resulting in treatment interruption was noted in
IPF patients treated with nintedanib at our hospital [16]. In this study, small physique was associated with the hepatotoxicity of nintedanib in IPF patients. Similarly, despite the relatively short observation period of the present study, the incidence and severity of nintedanibinduced AEs, such as AST/ALT elevation and anorexia, tended to be higher in this study than in the INPULSIS trials. A pharmacokinetic study confirmed that body weight is a statistically significant covariate that influences nintedanib exposure [17]. Based on these results, we speculated that small patients tended to have a high serum concentration, and were therefore more likely to develop AEs. Careful monitoring of AEs and dose adjustment of nintedanib is required especially for the small patients.

However, although the values of physique-related factors were significantly lower in the switch-group than in the pirfenidone-naïve group in the present study, only nintedanib-induced anorexia was significantly more frequent and severer in the switch-group than in the pirfenidone-naïve group, whereas no significant differences were observed in other AEs such as diarrhea and AST/ALT elevation. During the pirfenidone administration period before being switched to nintedanib, 53.3\% of patients exhibited anorexia with a 
Table 6 Comparison between the switch and pirfenidone-naïve groups

\begin{tabular}{|c|c|c|c|c|}
\hline & \multicolumn{2}{|l|}{ Switch-group $(n=30)$} & \multirow{2}{*}{$\begin{array}{l}\text { Pirfenidone- } \\
\text { naîve group } \\
(n=64)\end{array}$} & \multirow{2}{*}{$\begin{array}{l}p \\
\text { value }\end{array}$} \\
\hline & Just before initiation of pirfenidone & Just before initiation of nintedanib & & \\
\hline \multicolumn{5}{|l|}{ Characteristics } \\
\hline Age & $71.0[67.0,75.0]$ & $72.0[68.0,74.8]$ & $72.0[65.8,75.3]$ & $0.903^{*}$ \\
\hline Gender (male/female) & $24 / 6$ & $24 / 6$ & $53 / 11$ & $0.778^{*}$ \\
\hline \multicolumn{5}{|l|}{ Physique } \\
\hline Height (cm) & $165[158,169]$ & $165[158,169]$ & $164[160,170]$ & $0.958^{*}$ \\
\hline Body weight (kg) & $61.4[59.2,66.0]$ & $54.9[49.7,64.4]$ & $63.2[54.2,73.1]$ & $0.01^{*}$ \\
\hline Body mass index & $22.6[21.0,24.9]$ & $21.0[19.0,23.6]$ & $23.9[20.7,26.2]$ & $0.001^{*}$ \\
\hline Body surface area (DuBois, m²) & $1.69[1.62,1.76]$ & $1.59[1.48,1.72]$ & $1.68[1.54,1.82]$ & $0.063^{*}$ \\
\hline \multicolumn{5}{|l|}{ Lung function test } \\
\hline Forced vital capacity (L) & $2.36[1.78,3.52]$ & $1.68[1.34,1.99]$ & $2.21[1.74,2.66]$ & $0.001^{*}$ \\
\hline \% Forced vital capacity (\%) & $62.5[51.0,76.6]$ & $52.9[43.7,69.7]$ & $67.7[55.9,79.0]$ & $0.001^{*}$ \\
\hline \% DLco (\%) & $58.4[46.7,65.7]$ & $44.2[40.9,58.5]$ & $54.8[47.6,67.9]$ & $0.009^{*}$ \\
\hline \multicolumn{5}{|l|}{ Nintedanib } \\
\hline Administration period (month) & - & $5.30[2.84,11.8]$ & $6.13[3.02,14.5]$ & 0.415 \\
\hline Discontinue within 6 months & - & $16(53.3 \%)$ & $21(32.8 \%)$ & 0.072 \\
\hline \multicolumn{5}{|l|}{ Adverse events } \\
\hline AST/ALT elevation & - & 19 (63.3\%) & 46 (71.9\%) & 0.475 \\
\hline Diarrhea & - & $14(46.7 \%)$ & $34(53.1 \%)$ & 0.659 \\
\hline Anorexia & - & $14(46.7 \%)$ & $14(21.9 \%)$ & 0.028 \\
\hline Weight loss & - & $6(20.0 \%)$ & $6(9.3 \%)$ & 0.188 \\
\hline Nausea & - & $2(6.7 \%)$ & $11(17.1 \%)$ & 0.213 \\
\hline Fatigue & - & $3(10.0 \%)$ & $5(7.8 \%)$ & 0.707 \\
\hline
\end{tabular}

Categorical data are presented as numbers (percentages), whereas continuous data are presented as medians (interquartile ranges). ${ }^{*} p$ values were calculated by comparing the baseline characteristics of the switch-group just before nintedanib initiation and the baseline characteristics of the pirfenidone-naïve group. Fisher's exact test was used to compare categorical data, and the Mann-Whitney $\mathrm{U}$ test was used to compare continuous data

Abbreviations: DLCO diffusing capacity for lung carbon monoxide, AST aspartate aminotransferase, ALT alanine aminotransferase

CTCAE grade of $\geq 2$, and $56.7 \%$ of patients exhibited weight loss of $\geq 5 \%$ from baseline. Nevertheless, $76.6 \%$ of patients were switched to nintedanib with an interruption period of less than 1 month. The anorexia and weight loss occurring during the pirfenidone administration period persist until nintedanib initiation and might affect the incidence and severity of anorexia during the subsequent nintedanib treatment. In fact, among 14 patients who developed anorexia during the nintedanib administration period in the switch group, 11 patients $(78.6 \%)$ have already experienced anorexia during prior pirfenidone treatment. Furthermore, in the switch group of the present study, anorexia along with weight loss was one of the most common immediate causes of nintedanib discontinuation (Table 3), and this might also be the underlying cause of deterioration in physical condition or death. With regard to body weight loss, this could be an independent factor for decreased survival of IPF [18]. Thus, careful monitoring of body weight and the maintenance of nutritional status is mandatory in patients receiving anti-fibrotic therapies.

It is also noteworthy that nintedanib suppressed FVC decline compared with pirfenidone in $70 \%$ of patients who could undergo lung function tests before and after switching to nintedanib. As indicated both in a previous case series [7] and the present study, the intra-individual response to the two anti-fibrotic drugs may differ, and nintedanib is expected to suppress disease progression even after deterioration during the pirfenidone administration period. However, our results indicated that pirfenidone administration continued until the appearance of anorexia with a CTCAE grade of $\geq 2$ or weight loss is inappropriate to maximally utilize subsequent nintedanib. Considering that gastrointestinal AEs tended to occur early in the treatment course ( $<6$ months) of pirfenidone [19], dose modification or symptomatic therapy is required during this period [20]. When the gastrointestinal AEs of pirfenidone cannot be adequately managed, clinicians should consider switching to nintedanib early, 
Table 7 Details of adverse events of nintedanib in the switch and pirfenidone-naïve groups

\begin{tabular}{|c|c|c|c|c|c|c|c|c|}
\hline & \multicolumn{4}{|c|}{ Switch-group $(n=30)$} & \multicolumn{4}{|c|}{ Pirfenidone-naïve group $(n=64)$} \\
\hline & \multirow[t]{2}{*}{ Subjects } & \multicolumn{3}{|c|}{ CTCAE grade } & \multirow[t]{2}{*}{ Subjects } & \multicolumn{3}{|c|}{ CTCAE grade } \\
\hline & & 1 & 2 & 3 & & 1 & 2 & 3 \\
\hline \multicolumn{9}{|l|}{ Gastrointestinal } \\
\hline Anorexia & $14(46.7 \%)$ & 3 & 8 & 3 & $14(21.9 \%)$ & 8 & 2 & 4 \\
\hline Diarrhea & $14(46.7 \%)$ & 6 & 7 & 1 & $34(53.1 \%)$ & 20 & 10 & 4 \\
\hline Weight loss & $6(20.0 \%)$ & 3 & 3 & 0 & $6(9.3 \%)$ & 2 & 3 & 1 \\
\hline Nausea & $2(6.7 \%)$ & 0 & 2 & 0 & $11(17.1 \%)$ & 5 & 5 & 1 \\
\hline Vomiting & $2(6.7 \%)$ & 2 & 0 & 0 & $3(4.7 \%)$ & 3 & 0 & 0 \\
\hline Dyspepsia & 0 & 0 & 0 & 0 & $1(1.6 \%)$ & 0 & 1 & 0 \\
\hline \multicolumn{9}{|l|}{ Other } \\
\hline AST/ALT elevation & $19(63.3 \%)$ & 12 & 5 & 2 & $46(71.9 \%)$ & 28 & 12 & 6 \\
\hline Fatigue & $3(10.0 \%)$ & 1 & 1 & 1 & $5(7.8 \%)$ & 2 & 3 & 0 \\
\hline Abdominal pain & $3(10.0 \%)$ & 2 & 1 & 0 & $3(4.7 \%)$ & 3 & 0 & 0 \\
\hline Fever & $2(6.7 \%)$ & 2 & 0 & 0 & $4(6.3 \%)$ & 4 & 0 & 0 \\
\hline Acute exacerbation & $2(6.7 \%)$ & - & - & - & $3(4.7 \%)$ & - & - & - \\
\hline Pneumothorax & 0 & - & - & - & $3(4.7 \%)$ & - & - & - \\
\hline Rash & 0 & 0 & 0 & 0 & $2(3.1 \%)$ & 0 & 2 & 0 \\
\hline Hemoptysis & 0 & - & - & - & $1(1.6 \%)$ & - & - & - \\
\hline Cerebral infarction & 0 & - & - & - & $1(1.6 \%)$ & - & - & - \\
\hline Eosinophilia & 0 & - & - & - & $1(1.6 \%)$ & - & - & - \\
\hline Pneumatosis intestinalis & 0 & - & - & - & $1(1.6 \%)$ & - & - & - \\
\hline Hematochezia & 0 & - & - & - & $1(1.6 \%)$ & - & - & - \\
\hline Thrombocytopenia & 0 & - & - & - & $1(1.6 \%)$ & 1 & 0 & 0 \\
\hline
\end{tabular}

Categorical data are presented as numbers (percentages)

Abbreviations: AST aspartate aminotransferase, ALT alanine aminotransferase, CTCAE Common Terminology Criteria for Adverse Events

although continued treatment with pirfenidone may suppress further FVC decline and/or death even in patients with IPF who exhibit meaningful disease progression during treatment [21]. Moreover, when clinicians consider switching from pirfenidone to nintedanib due to gastrointestinal AEs, it would probably be better to have a certain washout period.

Recently, several clinical trials of the combined use of pirfenidone and nintedanib, which mainly evaluated the safety and pharmacokinetics, have been reported [22-24]. To proficiently use two anti-fibrotic drugs, there is a need to accumulate more cases and conduct further research into combination therapy or a treatment sequence involving nintedanib followed by pirfenidone administration.

A limitation of the present study was the retrospective single-center study design. Additionally, the number of included patients was small and the distribution of patients may have been skewed. There is a need to accumulate more cases from several hospitals and conduct further investigations for the validation of the present results. The short observation period was also a limitation when assessing long-term safety. Moreover, we didn't set specific criteria for the FVC decline to consider switching from pirfenidone to nintedanib in our center, thus leaving the attending physicians to determine whether pirfenidone treatment is to be continued or changed.

\section{Conclusions}

A high incidence of early termination of nintedanib was noted when patients were switched from pirfenidone. Anorexia and weight loss during prior pirfenidone treatment may increase the rate of early termination of subsequent nintedanib treatment. Further investigation is required to establish an optimal treatment strategy.

\section{Abbreviations}

AE: Adverse event; ALT: Alanine aminotransferase; AST: Aspartate aminotransferase; BMI: Body mass index; BSA: Body surface area;

CTCAE: Common Terminology Criteria for Adverse Events; DLco: Diffusing capacity for lung carbon monoxide; FVC: Forced vital capacity; IPF: Idiopathic pulmonary fibrosis; KL-6: Krebs von den Lungen-6; SP-D: Surfactant protein D

\section{Acknowledgements}

The authors would like to thank Morihito Takita (Center for Advancing

Translational Sciences, Kanagawa Prefectural Hospital Organization, Japan) for 
their advice concerning the statistical analysis. The authors would also like to thank Yukiko Ogasawara (Clinical Research Center, Kanagawa Cardiovascular and Respiratory Center, Japan) for extracting patient data.

\section{Funding}

This research received no specific grant from any funding agency in the public, commercial, or not-for-profit sectors.

\section{Availability of data and materials}

The datasets generated during and/or analyzed during the current study are available from the corresponding author on reasonable request.

\section{Authors' contributions}

SI and TOgura were involved in study conception and design. SI was involved in data acquisition; SI, AS, TB, TK, ET, RS, SS, HY, TOda, RO, HK, and TOgura were involved in the analysis and interpretation of the clinical data: $\mathrm{SI}, \mathrm{TB}$, and TI were involved in the analysis and interpretation of radiological findings; TB and $T T$ were involved in the analysis and interpretation of the pathological findings; $\mathrm{SI}, \mathrm{AS}, \mathrm{HY}$, and TOda were involved in drafting the manuscript; and SI, AS, TB, TK, ET, RS, SS, HY, TOda, RO, HK, TI, TT, and TOgura were involved in revising the manuscript. All authors have read and approved the final manuscript. TOgura would correspond to the last author of the author list.

\section{Ethics approval and consent to participate}

The Ethics Committee of the Kanagawa Cardiovascular and Respiratory Center approved the study protocol (approval date: January 16, 2018; approved number: KCRC-17-0040), and the need for patient consent was waived because this was a retrospective study and anonymity was secured.

\section{Consent for publication}

Not applicable.

\section{Competing interests}

S Ikeda, A Sekine, T Baba, T Katano, E Tabata, R Shintani, S Sadoyama, H Yamakawa, T Oda, R Okuda, H Kitamura, T Iwasawa, and T Takemura declare that no potential conflicts of interest exist with any companies/organizations whose products or services may be discussed in this article. T Ogura received an honorarium from Boehringer Ingelheim Co., Ltd. and Shionogi \& Co., Ltd.

\section{Publisher's Note}

Springer Nature remains neutral with regard to jurisdictional claims in published maps and institutional affiliations.

\section{Author details}

'Department of Respiratory Medicine, Kanagawa Cardiovascular and Respiratory Center, Tomioka-Higashi 6-16-1, Kanazawa-ku, Yokohama 236-0051, Japan. Department of Radiology, Kanagawa Cardiovascular and Respiratory Center, Yokohama 236-0051, Japan. ${ }^{3}$ Department of Pathology, Japanese Red Cross Medical Center, Tokyo 150-8935, Japan.

\section{Received: 2 July 2018 Accepted: 28 March 2019}

\section{Published online: 11 April 2019}

\section{References}

1. Martinez FJ, Collard HR, Pardo A, Raghu G, Richeldi L, Selman M, Swigris J, Taniguchi H, Wells AU. Idiopathic pulmonary fibrosis. Nat Rev Dis Primers. 2017;3:17074.

2. Raghu G. Pharmacotherapy for idiopathic pulmonary fibrosis: current landscape and future potential. Eur Respir Rev. 2017;26:170071.

3. King TE Jr, Bradford WZ, Castro-Bernardini S, Fagan EA, Glaspole I, Glassberg MK, Gorina E, Hopkins PM, Kardatzke D, Lancaster L, Lederer DJ, Nathan SD, Pereira CA, Sahn SA, Sussman R, Swigris JJ, Noble PW, ASCEND Study Group. A phase 3 trial of pirfenidone in patients with idiopathic pulmonary fibrosis. N Engl J Med. 2014;370:2083-92.

4. Richeldi L, du Bois RM, Raghu G, Azuma A, Brown KK, Costabel U, Cottin V, Flaherty KR, Hansell DM, Inoue Y, Kim DS, Kolb M, Nicholson AG, Noble PW, Selman M, Taniguchi H, Brun M, Le Maulf F, Girard M, Stowasser S, Schlenker-Herceg R, Disse B, Collard HR, INPULSIS Trial Investigators. Efficacy and safety of nintedanib in idiopathic pulmonary fibrosis. N Engl J Med 2014:370:2071-82

5. Corte T, Bonella F, Crestani B, Demedts MG, Richeldi L, Coeck C, Pelling K, Quaresma M, Lasky JA. Safety, tolerability and appropriate use of nintedanib in idiopathic pulmonary fibrosis. Respir Res. 2015;16:116.

6. Raghu G, Rochwerg B, Zhang Y, Garcia CA, Azuma A, Behr J, Brozek JL, Collard HR, Cunningham W, Homma S, Johkoh T, Martinez FJ, Myers J, Protzko SL, Richeldi L, Rind D, Selman M, Theodore A, Wells AU, Hoogsteden H, Schünemann HJ, American Thoracic Society; European Respiratory society; Japanese Respiratory Society; Latin American Thoracic Association. An official ATS/ERS/JRS/ALAT clinical practice guideline: treatment of idiopathic pulmonary fibrosis. An update of the 2011 clinical practice guideline. Am J Respir Crit Care Med. 2015;192:e3-e19.

7. Suissa S, Ernst P. The INPULSIS enigma: exacerbations in idiopathic pulmonary fibrosis. Thorax. 2015;70:508-10.

8. Rogliani P, Calzetta L, Cavalli F, Matera MG, Cazzola M. Pirfenidone, nintedanib and $\mathrm{N}$-acetylcysteine for the treatment of idiopathic pulmonary fibrosis: a systematic review and meta-analysis. Pulm Pharmacol Ther. 2016:40:95-103.

9. Crestani B, Quaresma M, Kaye M, Stansen W, Stowasser S, Kreuter M. Long-term treatment with nintedanib in patients with IPF: An update from INPULSIS ${ }^{\oplus}$-ON [abstract]. Eur Respir J. 2016;48(Suppl 60):[Abstract ID - OA4960].

10. Nathan SD, Albera C, Bradford WZ, Costabel U, Glaspole I, Glassberg MK, Kardatzke DR, Daigl M, Kirchgaessler KU, Lancaster LH, Lederer DJ, Pereira CA, Swigris JJ, Valeyre D, Noble PW. Effect of pirfenidone on mortality: pooled analyses and meta-analyses of clinical trials in idiopathic pulmonary fibrosis. Lancet Respir Med. 2017:5:33-41.

11. Milger K, Kneidinger N, Neurohr C, Reichenberger F, Behr J. Switching to nintedanib after discontinuation of pirfenidone due to adverse events in IPF. Eur Respir J. 2015;46:1217-21.

12. Raghu G, Collard HR, Egan JJ, Martinez FJ, Behr J, Brown KK, Colby TV, Cordier JF, Flaherty KR, Lasky JA, Lynch DA, Ryu JH, Swigris JJ, Wells AU, Ancochea J, Bouros D, Carvalho C, Costabel U, Ebina M, Hansell DM, Johkoh T, Kim DS, King TE Jr, Kondoh Y, Myers J, Müller NL, Nicholson AG, Richeldi L, Selman M, Dudden RF, Griss BS, Protzko SL, Schünemann HJ, ATS/ERS/ JRS/ALAT Committee on Idiopathic Pulmonary Fibrosis. An official ATS/ ERS/JRS/ALAT statement: idiopathic pulmonary fibrosis: evidence-based guidelines for diagnosis and management. Am J Respir Crit Care Med. 2011;183:788-824

13. Common Terminology Criteria for Adverse Events (CTCAE) ver.4.0. http:// ctep.cancer.gov/protocolDevelopment/electronic_applications/ctc.htm\#ctc_ 40. Accessed 17 Dec 2016

14. Boehringer Ingelheim [Internet], Japan: [Guide for appropriate use of nintedanib $\left.\left(\mathrm{Ofev}^{\oplus}\right)\right]$ ]. https://www.boehringerplus.jp/sites/all/themes/jp/nbi/ pdf/product-page/basic-documents/products/attach/pdf/ofe_cap_guide.pdf (in Japanese). Accessed 17 Dec 2016.

15. Kanda Y. Investigation of the freely available easy-to-use software "EZR" for medical statistics. Bone Marrow Transplant. 2013:48:452-8.

16. Ikeda S, Sekine A, Baba T, Yamanaka Y, Sadoyama S, Yamakawa H, Oda T, Okuda R, Kitamura H, Okudela K, Iwasawa T, Ohashi K, Takemura T, Ogura T. Low body surface area predicts hepatotoxicity of nintedanib in patients with idiopathic pulmonary fibrosis. Sci Rep. 2017;7:10811.

17. Schmid U, Doege C, Dallinger C, Freiwald M. Population pharmacokinetics of nintedanib in patients with idiopathic pulmonary fibrosis. Pulm Pharmacol Ther. 2017:10:136-43.

18. Nakatsuka Y, Handa T, Kokosi M, Tanizawa K, Puglisi S, Jacob J, Sokai A, Ikezoe K, Kanatani KT, Kubo T, Tomioka H, Taguchi Y, Nagai S, Chin K, Mishima M, Wells AU, Hirai T. The clinical significance of body weight loss in idiopathic pulmonary fibrosis patients. Respiration. 2018:96(4):338-47.

19. Valeyre D, Albera C, Bradford WZ, Costabel U, King TE Jr, Leff JA, Noble PW, Sahn SA, du Bois RM. Comprehensive assessment of the long-term safety of pirfenidone in patients with idiopathic pulmonary fibrosis. Respirology. 2014;19:740-7.

20. Ogura T, Azuma A, Inoue $Y$, Taniguchi H, Chida K, Bando M, Niimi Y, Kakutani S, Suga M, Sugiyama Y, Kudoh S, Nukiwa T. All-case post-marketing surveillance of 1371 patients treated with pirfenidone for idiopathic pulmonary fibrosis. Respir Investig. 2015;53:232-41.

21. Nathan SD, Albera C, Bradford WZ, Costabel U, du Bois RM, Fagan EA, Fishman RS, Glaspole I, Glassberg MK, Glasscock KF, King TE Jr, Lancaster L, Lederer DJ, Lin Z, Pereira CA, Swigris JJ, Valeyre D, Noble PW, Wells AU. Effect of continued 
treatment with pirfenidone following clinically meaningful declines in forced vital capacity: analysis of data from three phase 3 trials in patients with idiopathic pulmonary fibrosis. Thorax. 2016;71:429-35.

22. Ogura $T$, Taniguchi $H$, Azuma A, Inoue $Y$, Kondoh $Y$, Hasegawa $Y$, Bando $M$, Abe S, Mochizuki Y, Chida K, Klüglich M, Fujimoto T, Okazaki K, Tadayasu Y, Sakamoto W, Sugiyama Y. Safety and pharmacokinetics of nintedanib and pirfenidone in idiopathic pulmonary fibrosis. Eur Respir J. 2015;45:1382-92.

23. Vancheri C, Kreuter M, Richeldi L, Ryerson CJ, Valeyre D, Grutters JC, Wiebe S, Stansen W, Quaresma M, Stowasser S, Wuyts WA, INJOURNEY Trial Investigators. Nintedanib with add-on pirfenidone in idiopathic pulmonary fibrosis: results of the INJOURNEY trial. Am J Respir Crit Care Med. 2018;197:356-63.

24. Flaherty K, Sussman R, Pesci A, Nunes H, Acosta O, Petzinger U, Stauffer J, Gilberg F, Bengus M, Lancaster LH. Safety of the combined use of Pirfenidone and Nintedanib in patients with idiopathic pulmonary fibrosis (IPF): results from an interim analysis after 12 weeks [abstract]. Am J Respir Crit Care Med. 2017;195:[Abstract ID - A5398].

Ready to submit your research? Choose BMC and benefit from:

- fast, convenient online submission

- thorough peer review by experienced researchers in your field

- rapid publication on acceptance

- support for research data, including large and complex data types

- gold Open Access which fosters wider collaboration and increased citations

- maximum visibility for your research: over $100 \mathrm{M}$ website views per year

At BMC, research is always in progress.

Learn more biomedcentral.com/submissions 